\title{
Impact of Advance Pedagogy in Engineering and Outcome based Education
}

\author{
Sumit Das \\ JIS College of Engineering, \\ Information Technology, \\ Kalyani, 741235, India
}

\author{
S. Biswas, $\mathrm{PhD}$ \\ DETS, University of Kalyani, \\ Kalyani, 741235, India
}

\author{
Aniruddha Biswas \\ JIS College of Engineering, \\ Information Technology, \\ Kalyani, 741235, India
}

\begin{abstract}
In this paper, Engineering and Technological Education have been analyzed by the impact of Engineering Pedagogy and Outcome Base Education (EPOBE).To attract more youthful people into engineering and ensure that they are well equipped to meet future professional challenges, we have to know how successful engineers reflect and proceed when they are faced with challenging problems. The speculation is that, using a mixed (EPOBE) methods approach, where, we investigate and analyze how Engineering Pedagogy (EP) and OBE can be attenuated novice learner in engineering and technological education. It concludes by outlining future research to validate the habits of EPOBE approach in Engineering and Outcome Based Education (OBE) as well as to examine the internal changes in the learner.
\end{abstract}

\section{General Terms}

Graduate Attributes (GA), Engineering Pedagogy and Outcome Base Education (EPOBE), Engineering Pedagogy (EP), Advance Pedagogy (AP), Outcome Based Deliverable Content (OBDC), FLPI-Learning. Activity Based Learning (ABL), Traditional Education (TE).

\section{Keywords}

Engineering Pedagogy and Outcome Base Education (EPOBE), Engineering Pedagogy (EP), Advance Pedagogy (AP), Outcome Based Deliverable Content (OBDC), FLPILearning.

\section{INTRODUCTION}

We ask that authors follow some simple guidelines. In essence, we ask you to make your paper look exactly like this document. The easiest way to do this is simply to download the template, and replace the content with your own material. Our aim is to produce new insights about engineering design that could lead to improvements in curricula and classroom practices [8]. Our endeavor is to harmonize our research on design cognition and practice with further inquiry into practical applications of our findings. In this paper, we discuss one of our instructional efforts to bring research findings directly into classrooms. We designed Engineering Pedagogy and Outcome Base Education (EPOBE) wherein industrial and pedagogical aspects are analyzed and developed our own insights. Those insights became the catalysts for in-depth discussions and comparisons to our research findings. We will begin by setting the context and describe a few of the pedagogies currently used in engineering education to teach and learn engineering design. We will lead readers through our approach by presenting our research in much the same way we presented it to students in interactive sessions. We provide an overview of our design research, including how we collect, represent, and analyze the process, and then describe the activities by associating soft-skill, engineering advance pedagogy and outcome based education. We will use students' insights that were drawn directly from the sessions to fasten a discussion of our research findings which present in result and analysis section.

\section{LITERATURE SURVEY}

Over the earlier period, researchers at the University of Washington's Center for Engineering Learning \& Teaching conducted research on engineering design processes. Predominantly, here we studied how engineering undergraduates and experts solve engineering design problems [1-7]. Outcome-based education can eventually bring a great impact on students and prepare them for both exciting career and successful articulation in the computing field [13]. Outcome Based Assessment is only possible and meaningful and would bear fruits of Continuous Improvement of the Learning Process only if implemented after the understanding, appreciation and implementation of Outcome Based education [14]. Faculty responses to questions about their teaching philosophy inform a critical discussion of pedagogical aspects that are involved in the reshaping of the existing curriculum. The existing curriculum to OBE methods is going to be easy, yet we consider the transition as work in progress ensuring qualitative outcomes and continuous improvement. The process of transitioning from the contentdriven to the outcome-based curriculum is revealing opportunities as well as challenges that warrant further analysis [15]. The hallmark of OBE is "success for all" i.e. everyone has potential to acquire the three Cs: content, confidence and competence but the key lies in the deep engagement of all the learners, which is the heart of the OBE, emphasizing over all development of all the students by giving opportunity to all to internalize learning by constant practice. ABL empowers the learners to internalize the fundamental concepts, apply them in world situations to solve complex problems, to learn from their mistakes and link their knowledge with their schema blended with improved communication, creativity, social skills and leadership skills [16]. We studied key concept of OBE that is Learning Outcomes, Outcome Based Unit of Learning and Outcome Based Learning [12].

The challenges of OBE principle are that the different academicians interpret it in different ways. The inner realization of OBE principle is to, expand consciousness of one's spiritual nature as well as potential (essence of OBE), develop one's intuitive connection to universal wisdom (nature of learning); take full responsibility for one's life and experiences (major outcome measure), explore meditative exploration by quieting the conscious mind (key pedagogy), 
explore learner-controlled timing as well as group-enhanced experience (temporal structure) [17].

\section{EXPECTATIONS FROM ENGINEERING EDUCATION}

India produces a large number of engineers each year, but there are complaints from the industrial sector due to lack of the preferred quality of engineers. This is a concern since the success of the industries in India is dependent on the value and quality of the engineering education in the country. Most of the bright students in India nowadays opt to take engineering courses on completion of their pre-university education. This may be attributed to the increased number of people in the middle class and the upper class in conjunction with the predominant global market in the area of engineering and Information Technology. This demand for engineering courses has resulted to increased creation of engineering institutions but due to the low quality of education they deliver, there has been the problem of unemployment of an extensive number of the fresh graduates. In general the industry expects the following skill sets from the engineers:

- $\quad$ Attitude (Sincerity, Can-Do, Ownership/Motivation).

- Business Ethics/Honesty.

- Grooming/Confidence.

- Communication Skills.

- General Awareness.

- Basic Managerial Skills (Leadership, Teamwork, Time Management, etc.).

- Basic Sales and Customer Service (most entry level jobs require one of these).

- Domain Knowledge.

From the above skill sets, the soft skills are top most essential component which is observed in the pie chart. Positive attitude is seen to closely follow communication skills [17].

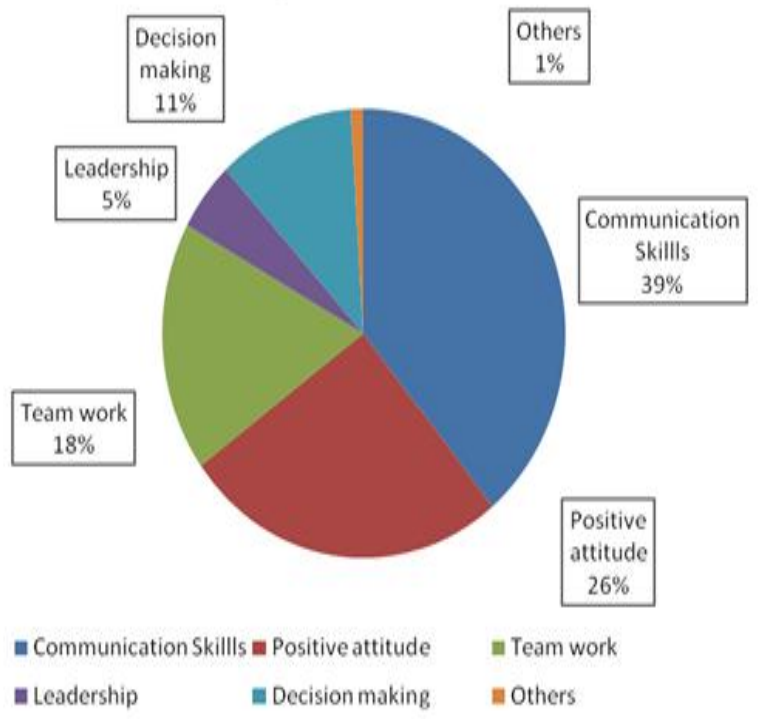

Fig.1. Soft-skill Expectation
To achieve the above skill sets from the engineers, the industries expectation to teach and train the students at Institutional end as per requirement of the industries. That is why the Outcome Base Education (OBE) is most important instead of Traditional Education (TE). Thanks to Govt. of India for taking initiatives regarding the matter say NAAC, NBA and applying strict rules \& regulation for accreditation and assessment.

\section{FRAMEWORK OF ENGINEERING EDUCATION}

The Engineering framework used as a tool for evaluating the degree to maintain academic standards, curricula, and teaching practices by maintaining Graduate Attributes (GA)[9].

The 12 Graduate Attributes:

1. (KB) A knowledge base for engineering: Demonstrated competence in university level mathematics, natural sciences, engineering fundamentals, and specialized engineering knowledge appropriate to the program.

2. (PA) Problem analysis: An ability to use appropriate knowledge and skills to identify, formulate, analyze, and solve complex engineering problems in order to reach substantiated conclusions.

3. (Inv.) Investigation: An ability to conduct investigations of complex problems by methods that include appropriate experiments, analysis and interpretation of data and synthesis of information in order to reach valid conclusions.

4. (Des.) Design: An ability to design solutions for complex, open-ended engineering problems and to design systems, components or processes that meet specified needs with appropriate attention to health and safety risks, applicable standards, and economic, environmental, cultural and societal considerations.

5. (Tools) Use of engineering tools: An ability to create, select, apply, adapt, and extend appropriate techniques, resources, and modern engineering tools to a range of engineering activities, from simple to complex, with an understanding of the associated limitations.

6. (Team) Individual and teamwork: An ability to work effectively as a member and leader in teams, preferably in a multi-disciplinary setting.

7. (Comm.) Communication skills: An ability to communicate complex engineering concepts within the profession and with society at large. Such ability includes reading, writing, speaking and listening, and the ability to comprehend and write effective reports and design documentation, and to give and effectively respond to clear instructions.

8. (Prof.) Professionalism: An understanding of the roles and responsibilities of the professional engineer in society, especially the primary role of protection of the public and the public interest.

9. (Impacts) Impact of engineering on society and the environment: An ability to analyze social and environmental aspects of engineering activities. Such ability includes an understanding of the interactions that engineering has with the economic, social, health, safety, 
legal, and cultural aspects of society, the uncertainties in the prediction of such interactions; and the concepts of sustainable design and development and environmental stewardship.

10. (Ethics) Ethics and equity: An ability to apply professional ethics, accountability, and equity.

11. (Econ.) Economics and project management: An ability to appropriately incorporate economics and business practices including project, risk, and change management into the practice of engineering and to understand their limitations.

12. (LL) Life-long learning: An ability to identify and to address their own educational needs in a changing world in ways sufficient to maintain their competence and to allow them to contribute to the advancement of knowledge.

\author{
Processes of Design (POD) \\ Problem and Background (POD-PB) \\ Plan and Implement (POD-PI) \\ Test and Evaluate (POD-TE) \\ Apply Science, Engineering, and Mathematics (SEM) \\ Engineering Thinking (EThink) \\ Conceptions of Engineers and Engineering (CEE) \\ Engineering Tools (ETool) \\ Issues, Solutions, and Impacts (ISI) \\ Ethics \\ Teamwork (Team) \\ Communication Related to Engineering (Comm-Engr)
}

Key Indicators

\section{Fig.2. Engineering Education framework based on GA}

The framework has 12 key indicators that, when taken together, summarize a quality engineering education for all students throughout their K-12 education. Fig. 2 provides a concise list of the key indicators of the framework [10]. The academicians get road map for making curriculum from GA, academic studies and industrial experience.

\section{PEDAGOGICAL APPROACHES IN ENGINEERING EDUCATION}

Innovation is about doing useful things differently: converting novel ideas and methods into solutions that meet new needs, or adding significant value to established products and services. In engineering education, new technological and practice requirements necessitate curriculum innovation, while innovation in educational practice can improve students' learning and faculty productivity. So, this goal can be achieved by the pedagogical approach and also by introducing advance-pedagogy in engineering. The key component of advance-pedagogy is micro-teaching, where each topic is analyzed and delivered with the mapping of real world philosophy. The content level analysis and mapping it with real world philosophy is the key idea of learning out come as depicted in fig. 3 .

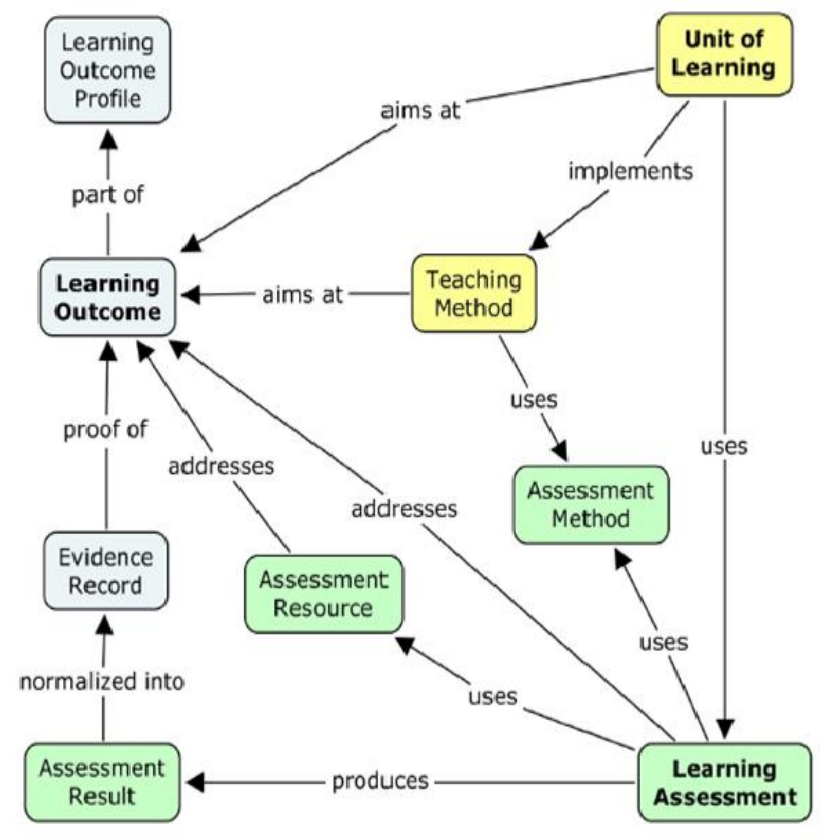

Fig.3. A concept mapping of $\mathrm{OBE}$ assessment [12]

Subject matter knowledge as shown in fig-3 is one form of content knowledge and includes knowledge of the facts and subject content, including the major concepts of the field, the relationships among concepts and a full understanding of the structures of the subject [9]. In science and engineering education, this includes theoretical facts of phenomena and propositions and their justifications. The mastering of the applications to everyday life and engineering is, of course, of crucial importance. The subject matter knowledge of an engineering educator should be built of, not only of academic studies, but also of a wide experience of working in the industry or as a researcher where the knowledge has been applied, proven and refined in practice.

\section{TRADITIONAL EDUCATION VS OBE}

In a traditional education system, the curriculum was defined by those who created textbooks rather than government bodies which assembled groups of stakeholders to create standards based on consensus of what students should know and be able to do. Traditional education, also known as back-to-basics, conventional education or customary education, refers to long-established customs that society traditionally used in schools. Some forms of education reform promote the adoption of progressive education practices, a more holistic approach which focuses on individual students' needs and self-control. In the eyes of reformers, traditional teachercentered methods focused on rote learning and memorization must be abandoned in favor of student-centered and taskbased approaches to learning. However, many parents and conservative citizens are concerned with the maintenance of objective educational standards based on testing, which favors a more traditional approach. Depending on the context, the opposite of traditional education may be progressive education, modern education, outcome based education (OBE) is shown in fig.6. 


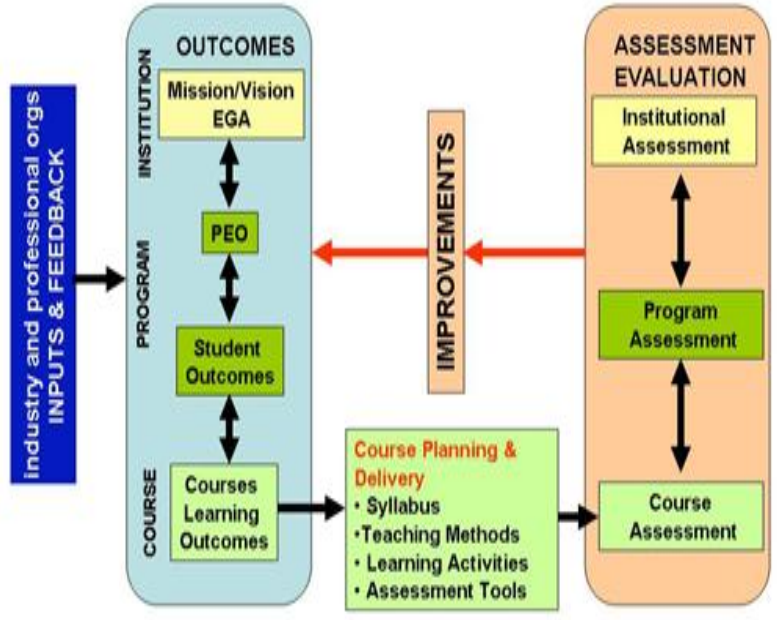

Fig.6.Outcome Based Framework [11]

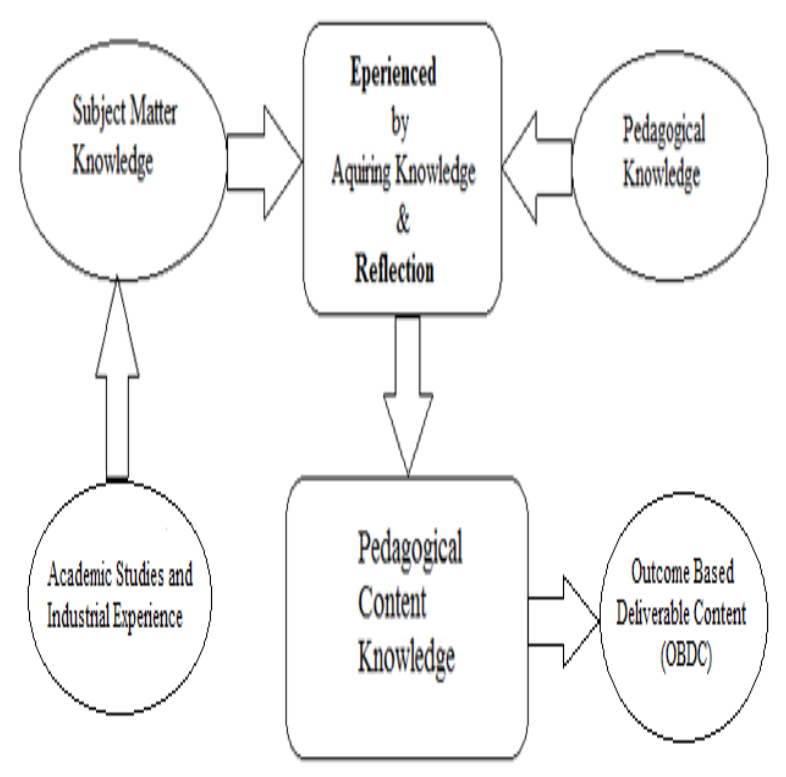

Fig.4. Structure of Engineering Pedagogy and OBE (EPOBE)

The Outcome Based Deliverable Content (OBDC) is sent to the student (class wise) in advance so that student can acquire knowledge prior to the class initiation which ensures deep learning (FLIP Learning [21]) by asking many questions to the teacher as well as fellow friends.

The above fig. 4 depicts how Outcome Based Deliverable Content (OBDC) can be developed from subject matter knowledge and pedagogical knowledge; whereas subject matter knowledge can be enhanced from academic studies and industrial experience. The impact of OBDC is to enhance skill because in industry skill is more important than knowledge. In our EPOBE, the entire GA reflects in PEO and BLOOM's revised taxonomy is used to design PEO as shown in fig.5.

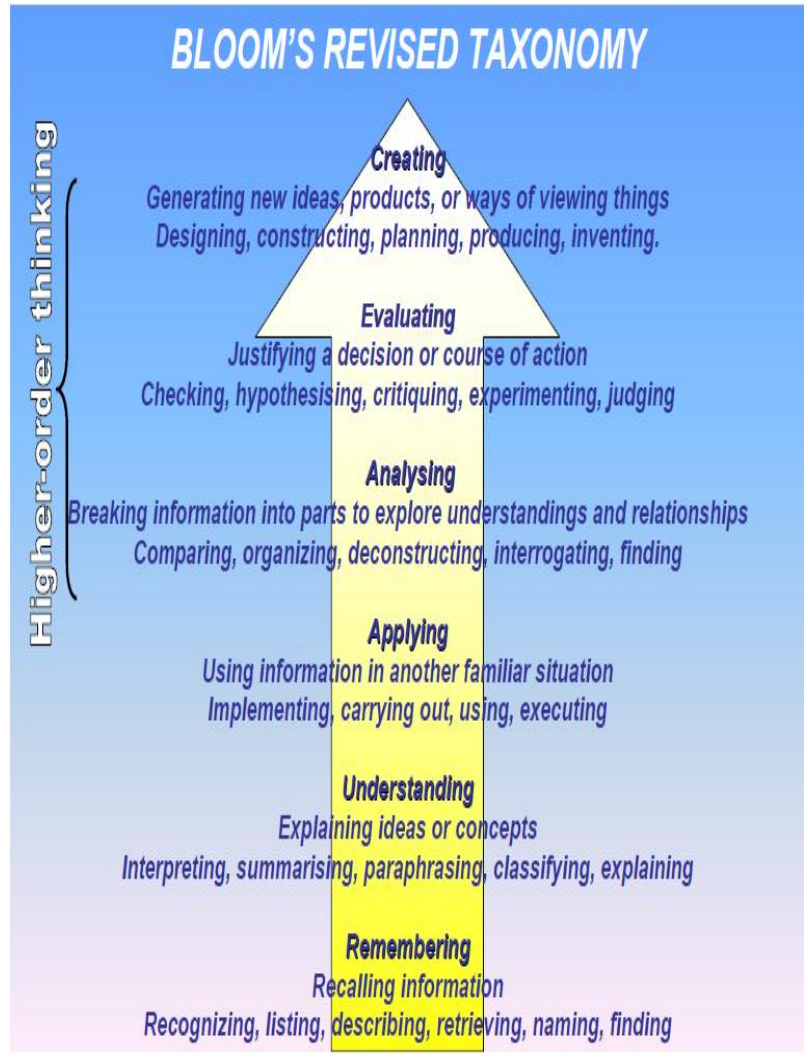

Fig.5. Bloom's Taxonomy [18]

BLOOM's taxonomy can be used to identify different kind of pedagogical knowledge in the contents as well as to design OBDC. Whereas pedagogy include "the art, science or profession of teaching" and "the study of the methods and activities of teaching". Pedagogy may be thought of as a subset of education; pedagogy focuses on teaching - who and what is taught and how it is taught - whilst education is a broader term encompassing the institutions in which teaching takes place, policies governing how institutions operate [20].

\section{RESULTS AND ANALYSIS}

The educations are supplied according to the macro-level curriculum which is designed based on OBE, but faculties use to deliver the content at micro-level. Advance Pedagogy is the platform to develop micro-level teaching say in our country India, National Institute of Technical Teachers Training and Research (NITTTR) is such kind of platform. As per analysis the following fig.7 depicts the improvement of EPOBE over traditional lecture based learning. 


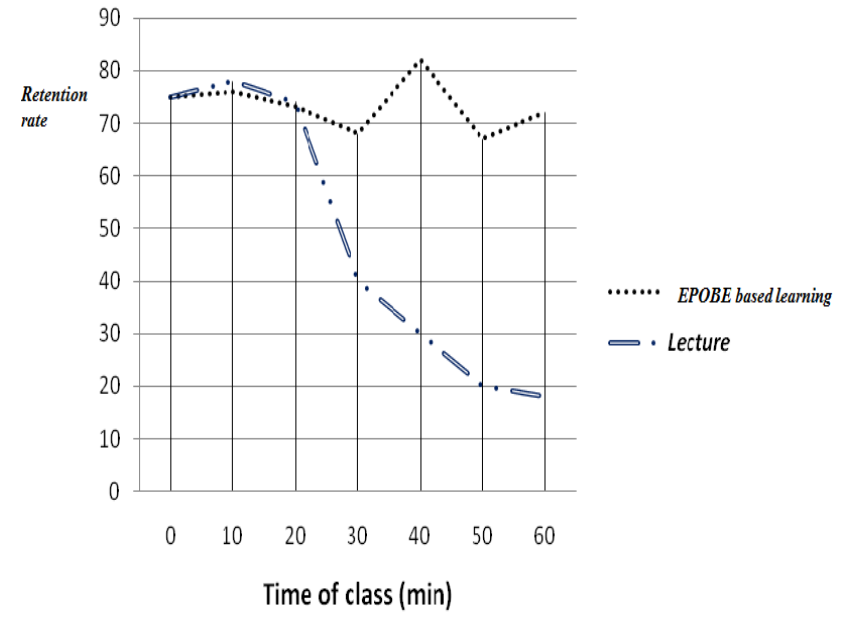

Fig.7. Time vs. Retention rate of EPOBE and Traditional Lecture base learning [19]

There is some speculation of our EPOBE structure of educations:

- Promotes high prospect and superior learning for all students as well as teaching for all teachers,

- Prepares students for lifelong learning and cope up with recent trend,

- Fosters more authentic forms of assessment and acquires meta-cognitive knowledge

- Encourages decision-making at all levels including: Curriculum, Teaching methods, Institution structure and Management also.

For instance, it's a pride that "JIS College of Engineering an Autonomous Institution" has been introducing the same concept and acquiring the results as mentioned.

\section{CONCLUSIONS}

In this paper, we've introduced road-map of OBE and Engineering Pedagogy as an advance impact of OBE which is designed as EPOBE. The EPOBE structure is associated with soft-skill, engineering education framework based on Graduate Attributes, OBE framework and advance engineering pedagogy. The blow of soft-skill and advance pedagogy reflect prospect of EPOBE by amalgamating FLIPLearning. The impact of EPOBE is speculated as a plus point of OBE for the recent and future learning-teaching.

\section{REFERENCES}

[1] C. J. Atman and I. Nair, Engineering in Context: An Empirical Study of Freshmen Students' Conceptual Frameworks. J. of Eng. Educ., 85(4), 1996, pp. 317-326.

[2] D. Kilgore, C. J. Atman, K. Yasuhara, T. J. Barker and A. Morozov, Considering Context: A Study of First-Year Engineering Students. J. of Eng. Educ., 96(4), 2007, pp. 321-334.

[3] M. E. Cardella, C. J. Atman and R. S. Adams, Mapping Between Design Activities and External Representations for Engineering Student Designers. Design Studies, 27(1), 2006, pp. 5-24.

[4] C. J. Atman, J. R. Chimka, K. M. Bursic and H. L. Nachtmann, A Comparison of Freshman and Senior
Engineering Design Processes. Design Studies, 20(2), 1999, pp. 131-152.

[5] C. J. Atman, R. S. Adams, M. E. Cardella, J. Turns, S. Mosborg, and J. Saleem. Engineering Design Processes: A Comparison of Students and Expert Practitioners. J. of Eng. Educ., 96(4), 2007, pp. 359-380.

[6] S. Mosborg, M. E. Cardella, J. J. Saleem, C. J. Atman, R. S. Adams, J. Turns and K. Deibel, Engineering Design Expertise Study, CELT Technical Report. CELT-06-01, Seattle, WA: Center for Engineering Learning and Teaching, University of Washington, 2006.

[7] C. J. Atman and J. Turns, Studying Engineering Design Learning: Four Verbal Protocol Studies, Design Knowing and Learning: Cognition in Design Education, Amsterdam; New York, 2001, pp. 14-37.

[8] J. Turns, R. S. Adams, A. Linse, J. Martin and C. J. Atman, Bridging from Research to Teaching in Undergraduate Engineering Design Education. I. J. of Eng. Educ., 20(3), 2004, pp. 379-390.

[9] www.mun.ca/engineering/undergrad/graduateattributes.p df"

[10] "A Framework for Quality K-12 Engineering Education: Research and evelopment",Tamara J. Moore, Aran W. Glancy, Kristina M. Tank, Jennifer A. Kersten, and Karl A. Smith, Micah S. Stohlmann ,Journal of Pre-College Engineering Education Research 4:1 (2014) 1-13

[11] "www.google.co.in/search?q=outcome+based+framewor k\&biw $=1252 \& b i h=578 \&$ source $=1 \mathrm{nms} \&$ tbm $=i s c h \& s a=X$ \&ved=0ahUKEwjeuJS06sPOAhUFKo8KHWDMDqsQ_ AUIBigB\#imgrc=4UmtEt43BJyX8M\%3A"

[12] Michael Dernt11, Susanne Neumann2, Petra Oberhuemer2 ," Aligning Assessment with Learning Outcomes in Outcome-based Education", /10/\$25.00 C2010 IEEE April 14 - 16, 2009, Madrid, SPAIN IEEE EDUCON Education Engineering 2010 - The Future of Global Learning Engineering Education Session T1A Page 1

[13] Gary K. W. Wong, H. Y. Cheung, "Outcome-Based Teaching and Learning in Computer Science Education at Sub-degree Level", International Journal of Information and Education Technology, Vol. 1, No. 1, April 2011, ISSN: 2010-3689.

[14] Chandra R. Sekhar, Omer Farook and Essaid Bouktache, "Continuous Improvement Process Based on Outcome Based Education", Proceedings of The 2008 IAJC-IJME International Conference ISBN 978-1-60643-379-9.

[15] Liliya Akhmadeeva, Maureen Hindy, Carolyn J. Sparrey, "Overcoming Obstacles To Implementing An OutcomeBased Education Model: Traditional Versus Transformational Obe” ,Proc. 2013 Canadian Engineering Education Association (CEEA13) Conf., CEEA13; Paper 145 Montreal, QC; June 17-20, 2013 - 1 of 5

[16] SujataWadhwa, Audrey Barlow, Siddharthsinh Jadeja, "Activity Based Learning: Overcoming problems in implementing OBE in Engineering Education during transition phase.", 43rd Annual SEFI Conference June 29 - July 2, 2015Orléans, France 
Communications on Applied Electronics (CAE) - ISSN : 2394-4714

Foundation of Computer Science FCS, New York, USA

Volume 6-No.8, March 2017-www.caeaccess.org

[17] https://www.ied.edu.hk/obl/files/pratical_guide_5.pdf

[18] https://tlc.iitm.ac.in/PDF/Blooms\%20Tax.pdf

[19] https://www.nescent.org/eog/documents/IntrotoActiveLe arning.ppt
[20] https://www.heacademy.ac.uk/system/pedagogic_researc h_guide_final_version_0.

[21] https://www.scholarworks.montana.edu/xmlui/bitstream/ handle/1/1790/MarloweC0812.pdf? 